\title{
Erratum to: Assessing Coparenting Relationships in Daily Life: The Daily Coparenting Scale (D-Cop)
}

\author{
Brandon T. McDaniel ${ }^{1} \cdot{\text { Douglas M. } \text { Teti }^{2} \cdot \text { Mark E. Feinberg }}^{3}$
}

/ Published online: 2 June 2017

(C) Springer Science+Business Media New York 2017

Erratum to: J Child Fam Stud (2017) DOI 10.1007/s10826-017-0762-0

The original version of this article unfortunately contained a mistake. The sixth row in Table 6 was missed by the typesetter. The original article was corrected. The corrected table is given below.

The online version of the original article can be found at doi:10.1007/ s10826-017-0762-0.

Brandon T. McDaniel

btmcdaniel.phd@gmail.com

1 Illinois State University, Campus Box 5060, Normal, IL 61790, USA

2 The Pennsylvania State University, 119 Health and Human Development Bldg., University Park, PA 16802, USA

3 The Pennsylvania State University, 314 Biobehavioral Health Bldg., University Park, PA 16802, USA 
Table 6 Daily Coparenting Scale (D-Cop)

Please select the response that best describes the way you feel about how you and your partner worked together as parents TODAY

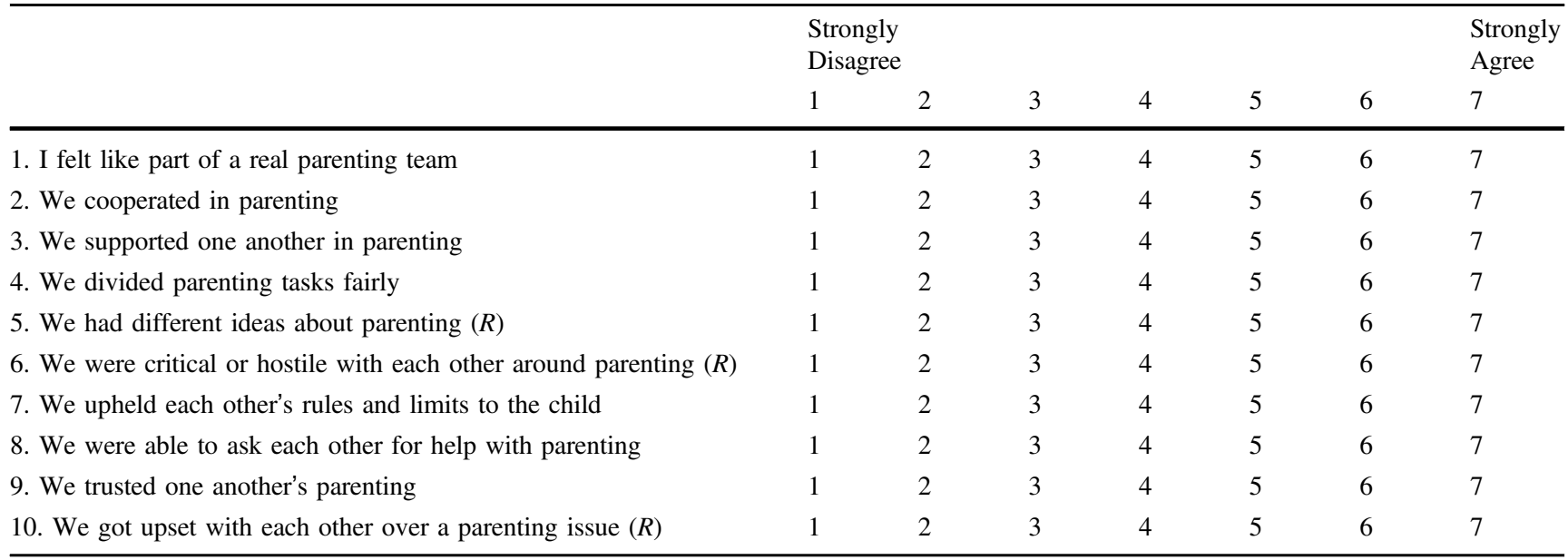

Overall D-Cop Score (10 items) = Average of all items. Items 5, 6, and 10 are reverse coded

Positive D-Cop Score (7 items) = Average of items 1, 2, 3, 4, 7, 8, and 9

Negative D-Cop Score (3 items) = Average of items 5, 6, and 10 